\title{
PROCEDIMIENTO PARA EL CULTIVO E IDENTIFICACIÓN DE CÉLULAS MADRE OBTENIDAS DE LIPOASPIRADO HUMANO CON FINES DE INVESTIGACIÓN
}

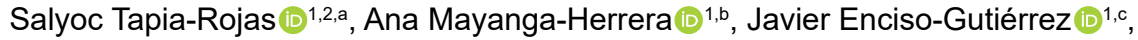 \\ Patricio Centurion (10) ${ }^{3, \mathrm{~d}}$, José Amiel-Pérez (1) ${ }^{1, e}$ \\ 1 Laboratorio de Cultivo Celular e Inmunología, Instituto de Medicina Regenerativa, Universidad Científica del Sur, Lima, Perú. \\ 2 Universidad Nacional Mayor de San Marcos, Lima, Perú. \\ 3 Clínica Delgado, Lima, Perú.

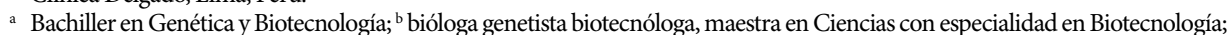 \\ ${ }^{c}$ médico veterinario zootecnista, magíster en Ciencias Veterinarias con mención en Patología; ${ }^{\mathrm{d}}$ médico cirujano, especialista \\ en Cirugía Plástica; ${ }^{\mathrm{e}}$ químico farmacéutico, doctor en Farmacia y Bioquímica.
}

\section{RESUMEN}

Las células madre humanas nacen con la creación de la vida misma y algunas de estas permanecen durante toda la vida. Por consiguiente, se pueden hallar en tejidos adultos y utilizarlas para investigaciones a nivel básico y aplicado. Actualmente, en nuestro país existe un creciente interés en el estudio y aplicación de células madre; sin embargo, existe poco conocimiento acerca del procedimiento para su identificación. Es por ello que este artículo tiene como objetivo dar a conocer, desde un punto de vista práctico, un procedimiento para el cultivo e identificación de células madre/estromales obtenidas de lipoaspirado humano (Adipose Stem Cells) con fines de investigación, el cual incluye la caracterización a nivel de inmunofenotipo, el potencial de diferenciación celular, la expresión génica y el control de calidad del cultivo celular, que sirva de apoyo para los profesionales de la comunidad científica peruana que deseen desarrollar esta línea de investigación.

Palabras clave: Células Madre; Medicina Regenerativa; Tejido Adiposo; Aislamiento Celular, Cultivo Primario de Células (fuente: DeCS BIREME).

\section{PROCEDURE FOR CULTURE AND IDENTIFICATION OF STEM CELLS FROM HUMAN LIPOASPIRATE FOR RESEARCH PURPOSES}

\section{ABSTRACT}

Human stem cells are born with the creation of life itself and some of them remain throughout life. Therefore, they can be found in adult tissues and used for basic and applied research. Currently, in our country there is a growing interest in the study and application of stem cells; however, little is known about the identification procedure. For this reason, this study aims to present, from a practical point of view, a procedure for the culture and identification of stem/stromal cells obtained from human lipoaspirate (Adipose Stem Cells), for research purposes. This procedure includes the immunophenotype characterization, cell differentiation potential, gene expression and cell culture quality control; and will serve as support for Peruvian scientific community professionals who wish to develop this line of research.

Citar como: Tapia-Rojas S, MayangaHerrera A, Enciso-Gutiérrez J, Centurión P, Amiel-Pérez J. Procedimiento para el cultivo e identificación de células madre obtenidas de lipoaspirado humano con fines de investigación. Rev Peru Med Exp Salud Publica. 2020;37(3):547-

53. doi: https://doi.org/10.17843/ rpmesp.2020.373.5201

Correspondencia: Salyoc Tapia Rojas; Carretera Antigua Panamericana Sur Km. 19 (Altura de los Pantanos de Villa), Lima, Perú; salyoc.tapia@unmsm.edu.pe

Recibido: 04/02/2020 Aprobado: 27/05/2020 En línea: $12 / 08 / 2020$
Keywords: Stem Cells; Regenerative Medicine; Adipose Tissue; Cell Separation; Primary Cell Culture (source: MeSH NLM).

\section{INTRODUCCIÓN}

Durante las últimas décadas, las células madre han generado gran interés debido a su potencial uso para el tratamiento de diversas enfermedades ${ }^{(1)}$. Estas se caracterizan por autorrenovarse y diferenciarse en distintos linajes celulares; de acuerdo a su origen pueden ser células madre embrionarias o adultas ${ }^{(2,3)}$. El uso de las primeras es limitado debido a los problemas éticos que acarrean ${ }^{(4)}$; en cuanto a las células madre adultas, estas se pueden hallar en diferentes tejidos como la médula ósea roja, el cordón umbilical, la placenta, la pulpa dental, el tejido adiposo, entre otros, cuyo uso no acarrea ningún problema ético. 
Las células madre/estromales mesenquimales (MSC, por sus siglas en inglés) son células madre adultas. Han sido identificadas y caracterizadas por su adhesión al plástico, presencia de los marcadores de superficie CD90, CD73 y CD105 en más del 95\% de células, ausencia de los marcadores CD45, CD34, CD14 o CD11b, CD79a o CD19, HLA-DR y diferenciación in vitro, criterios mínimos que fueron establecidos por la Sociedad Internacional de Terapia Celular (ISCT, por sus siglas en inglés) en el $2006{ }^{(5)}$. Posteriormente, en 2013, la misma ISCT estableció criterios específicos para identificar células madre/estromales derivadas de tejido adiposo (ASC, por sus siglas en inglés) en los cuales se mantienen los marcadores positivos antes mencionados, añadiendo como marcador positivo opcional al CD13; además, sugirió el uso de marcadores adicionales que permitan cuantificar la potencialidad de estas células ${ }^{(6)}$.

Diversos estudios han encontrado que los factores de transcripción Oct4, Sox-2 y Nanog cumplen un papel importante en el mantenimiento de la autorrenovación y el potencial de diferenciación, los cuales en conjunto forman parte de una red reguladora transcripcional en las células madre ${ }^{(7,8)}$.

Actualmente, en nuestro país existe un creciente interés en el estudio y la aplicación de células madre. Sin embargo, se desconoce la correcta identificación de ASC, por ejemplo, según una encuesta realizada a médicos peruanos sobre el proceso de identificación de ASC ${ }^{(9)}$, el $51 \%$ piensa que a veces, pocas veces o nunca se realiza este proceso; además, el $28 \%$ desconoce completamente este aspecto. Asimismo, dentro de los pocos estudios realizados con ASC en el Perú algunos describen un procedimiento incompleto y la mayoría no describe este procedimiento ${ }^{(10-13)}$, lo cual genera desconfianza sobre la verdadera identidad de las células que se están estudiando o aplicando. En consecuencia, esta realidad nos lleva a formularnos la siguiente pregunta: ¿realmente se están realizando los procedimientos adecuados para identificar células madre?

Es por eso por lo que este artículo tiene como objetivo presentar, desde un punto de vista práctico y experimental, un procedimiento para el cultivo e identificación de ASC que sirva de apoyo para los profesionales de la comunidad científica peruana que deseen desarrollar esta línea de investigación.

\section{PROCEDIMIENTO}

El procedimiento detallado a continuación es el resultado de integrar diferentes protocolos y es importante mencionar que todos los equipos usados en la aplicación de este procedimiento se encontraban operativos y debidamente calibrados.

\section{Obtención de muestra de lipoaspirado}

La muestra de lipoaspirado que se usó en este trabajo se obtuvo en la Clínica Delgado, en un ambiente estéril median- te la técnica One S.T.E.P $\mathrm{P}^{\mathrm{m}}$ (One Selective Tissue Engineering Photostimulation) ${ }^{(14)}$, a partir del tejido celular subcutáneo periumbilical de una mujer peruana libre de enfermedades infecto-contagiosas, quien brindó su consentimiento informado. La muestra colectada fue transportada a $48^{\circ} \mathrm{C}$ al Laboratorio de Cultivo Celular de la Universidad Científica del Sur, en Lima.

\section{Aislamiento y cultivo celular}

Para el aislamiento de ASC, se siguió el protocolo de Min Zhu et al. ${ }^{(15)}$, el cual se detalla a continuación. Colocar la muestra en un beaker de $250 \mathrm{~mL}$, realizar tres lavados con PBS 1X hasta observar que el tejido adiposo se torne de un color amarillo/dorado y descartar todo el infranadante como se muestra en la Figura 1A y 1B. Agregar colagenasa al $0,1 \%$ filtrada en un volumen igual al de la muestra e incubar a $37^{\circ} \mathrm{C}$ por una hora con agitaciones cada 15 minutos. Repartir alícuotas de $25 \mathrm{~mL}$ del infranadante resultante de la digestión enzimática, donde se encuentra la fracción del estroma vascular, en tubos de centrifuga de $50 \mathrm{~mL}$. Después añadir $25 \mathrm{~mL}$ de medio DMEM/Ham's F-12 suplementado al $10 \%$ con suero fetal bovino (SFB) y antibióticos $1 \mathrm{X}$ (DMEM completo) a cada tubo y dejar a temperatura ambiente por cinco minutos para inactivar la colagenasa, centrifugar a 2776 revoluciones por minuto (RPM) por diez minutos, descartar el sobrenadante, combinar los pellets obtenidos en un solo tubo y resuspender hasta un volumen de $25 \mathrm{~mL}$ de medio DMEM completo. Centrifugar a 2776 RPM por diez minutos, retirar el sobrenadante, resuspender el pellet resultante en $5 \mathrm{ml}$ de PBS 1X (Figura 1C) y verter en un colador celular de $100 \mu \mathrm{m}$, centrifugar nuevamente a 2776 RPM por diez minutos, descartar el sobrenadante y resuspender el pellet en $50 \mathrm{~mL}$ de DMEM completo. Finalmente, repartir aproximadamente $8 \mathrm{~mL}$ de la suspensión celular por placa en seis placas de $100 \mathrm{~mm}$ e incubar a $37^{\circ} \mathrm{C}$ con $5 \%$ de $\mathrm{CO}_{2}$ hasta que las células alcancen una confluencia celular aproximada del 80\% como se observa en la Figura 1D.

Aplicando este protocolo, observamos que después de 12 horas del inicio de la incubación, las células sembradas se adhirieron a la placa, llegando a la confluencia al sexto día y formando colonias observadas en la Figura 3A, la cual es una característica fenotípica de células madre/estromales mesenquimales.

\section{Citometría de flujo}

Para la caracterización del inmunofenotipo de las ASC se usaron anticuerpos monoclonales CD73-APC, CD90-FITC, CD105-PerCP-Cy ${ }^{\text {mim }} 5,5$ (marcadores positivos) y CD45-PE, CD34-PE, CD11b-PE, CD19-PE y HLA-DR-PE (marcadores negativos) del kit MSC human BD Stemflow ${ }^{\text {mim }}$ siguiendo las instrucciones del fabricante (BD Biosciences, EUA). Repartir alícuotas de $10^{6}$ células en $100 \mu \mathrm{L}$ de buffer de tinción $\mathrm{BD}$ Pharmingen $^{\text {max }}$ para cada muestra, adicionar los anticuerpos 


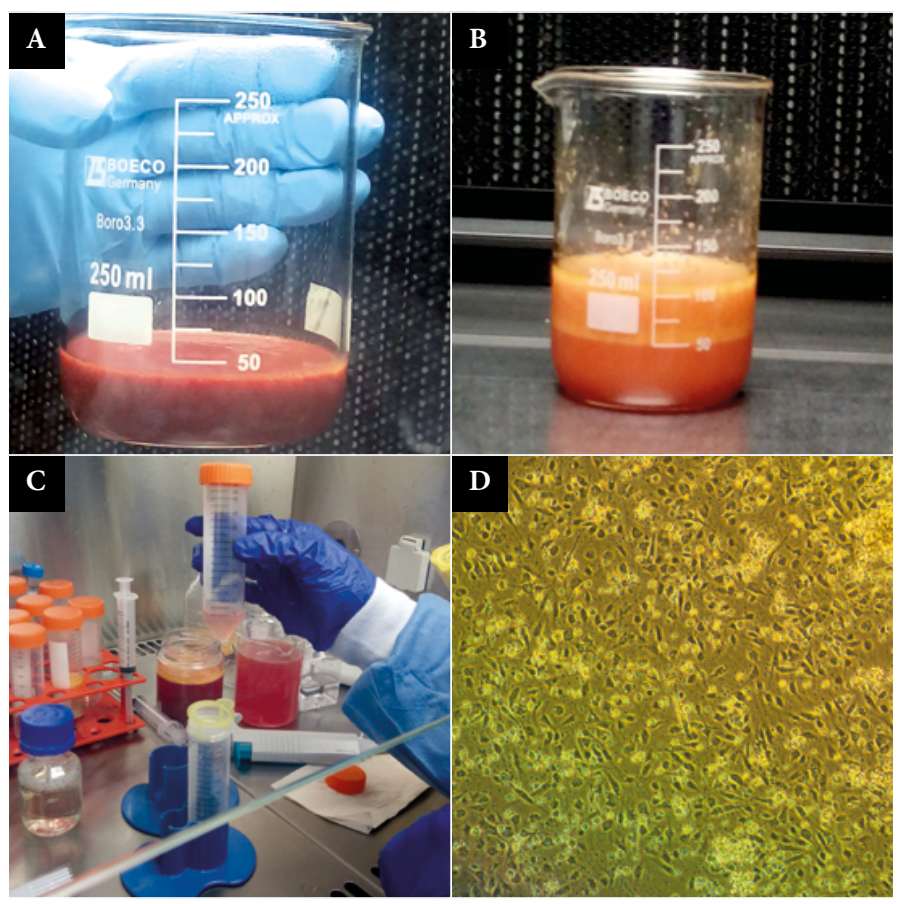

Figura 1. Procesado y cultivo primario de células madre/estromales derivadas de tejido adiposo. A. Muestra de lipoaspirado. B. Muestra durante el último lavado con PBS 1X, se observan tres capas, una capa superior oleosa, una intermedia de tejido adiposo y una inferior del infranadante. C. Pellet celular resuspendido en medio de cultivo. D. Día cero de cultivo primario de células madre/estromales derivadas de tejido adiposo (A.T. $100 \mathrm{X}$ ).

monoclonales en la cantidad indicada en el kit BD Stemflow ${ }^{\text {Tm }}$ y dejar a temperatura ambiente durante 15 minutos en oscuridad. Después, lavar con $1 \mathrm{~mL}$ de PBS 1X, centrifugar a $300 \mathrm{x}$ g por cinco minutos y resuspender en $300 \mu \mathrm{L}$ de buffer de tinción. Por último, analizar las muestras en un citómetro de flujo, en este caso se usó el citómetro de flujo FacsCanto II.

Después de realizar este paso se observó que las ASC expresaron los inmunofenotipos de membrana CD44, CD73, CD90 y CD105 en los porcentajes de 99,2; 97,9; 99,7 y 83,6\%, respectivamente para cada marcador positivo y un $0,3 \%$ para los inmunofenotipos CD11b, CD19, CD34, CD45 y HLA-DR, que son marcadores negativos. Los resultados obtenidos se observan en la Figura 2.

\section{Diferenciación celular}

Seguir los protocolos recomendados en los kits de diferenciación osteogénica, adipogénica y condrogénica (StemPro, Gibco) con ligeras modificaciones. Repartir las ASC por triplicado a 2000, 3900 y 80000 células por pocillo en una placa de 96 pocillos en medio DMEM completo; al día siguiente cambiar el medio de cultivo por medios suplementados para diferenciación osteogénica, adipogénica y condrogénica; y cambiar los medios cada tres días durante 21, 10 y 15 días, respectivamente; para inducir la diferenciación celular. Luego, realizar una tinción selectiva para corroborar la diferenciación. Lavar cada pocillo con PBS 1X, fijar las células con una solución de formaldehído al 4\% durante 30 minutos y lavar dos veces con
PBS 1X. Luego, teñir cada grupo con los colorantes Alzarin red $\mathrm{S}$ por tres minutos, Oil red $\mathrm{O}$ por 20 minutos y Alcian Blue $8 \mathrm{GS}$ por 30 minutos. Después de la tinción, verificar en un microscopio invertido la diferenciación celular.

En la Figura 3 observamos que las ASC diferenciadas a osteocitos presentaron depósitos de calcio que se tiñeron de color rojo con el colorante Alzarin red S (Figura 3B), las células diferenciadas a adipocitos mostraron gotas lipídicas de diferentes dimensiones en el citoplasma que se confirmó con el colorante Oil red O (Figura 3C), y por último las células diferenciadas a condrocitos formaron un conglomerado celular que se tiñe de color azul con Alcian Blue 8GS debido a la presencia de heteroglicanos (Figura 3D).

Los procedimientos descritos a continuación no se encuentran dentro de los criterios mínimos de la ISCT ${ }^{(5)}$, pero se incluyeron para verificar el estado de potencialidad de las ASC y la esterilidad del cultivo.

\section{Ensayo de reacción en cadena de la polimerasa de transcripción inversa (RT-PCR)}

Para la extracción de ARN se usó el kit innuPREP DNA/RNA (Analytik Jena) y para la síntesis del ADN complementario se usó el kit OneScript cDNA synthesis (abm), siguiendo los protocolos recomendados por los fabricantes. Para la reacción en cadena de la polimerasa (PCR), se usó $1 \mu \mathrm{L}$ de ADNc, $1 \mu \mathrm{L}$ de los cebadores a $10 \mu \mathrm{M}, 10 \mu \mathrm{L}$ del Kodaq $2 \mathrm{X}$ PCR MasterMix (abm) y $7 \mu \mathrm{L}$ de agua libre de nucleasas. 


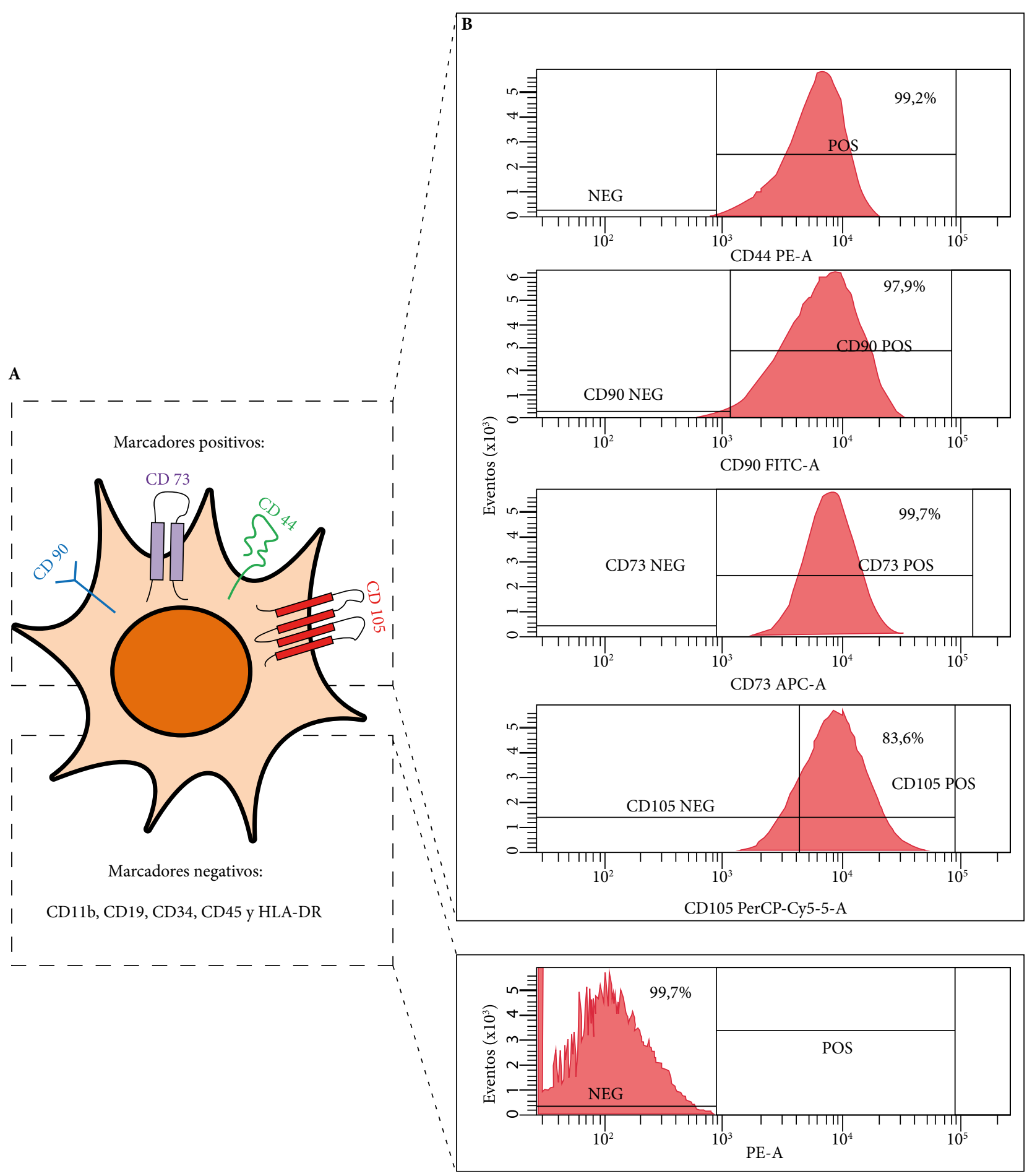

Figura 2. Ensayo de citometría de flujo para evaluar los inmunofenotipos de membrana de ASC. A. Esquema de una célula madre/estromal derivada de tejido adiposo que muestra los antígenos característicos de célula madre mesenquimales (marcadores positivos: CD44, CD73, CD90 y CD105), así como la ausencia de marcadores de diferenciación (negativos) tales como CD11b, CD19, CD34, CD45 y HLA-DR. B. Gráfica de histogramas en función del número de eventos versus la intensidad de fluorescencia emitida por el fluorocromo del marcador.

Las secuencias de los cebadores se detallan en el material suplementario. Las condiciones del termociclador son un ciclo de denaturación de $94{ }^{\circ} \mathrm{C}$ por tres minutos, 35 ciclos de denaturación a $94{ }^{\circ} \mathrm{C}$ por 30 segundos, hibridación y extensión a $72{ }^{\circ} \mathrm{C}$ por 60 segundos y un paso final de extensión a $72{ }^{\circ} \mathrm{C}$ por 60 segundos. Visualizar los productos amplificados en un gel de agarosa al $2 \%$ teñido con bromuro de etidio.

En la Figura 4B se observa el resultado de la RT-PCR de las ASC en donde se evidencia la expresión de los genes 
Diferenciación celular
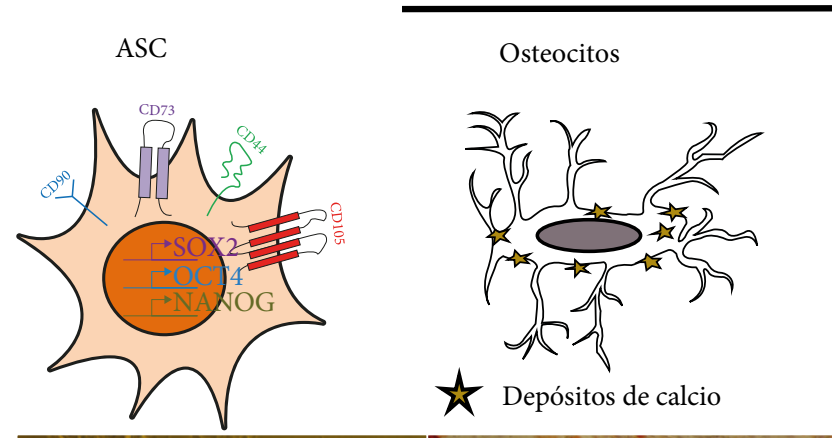

Adipocitos

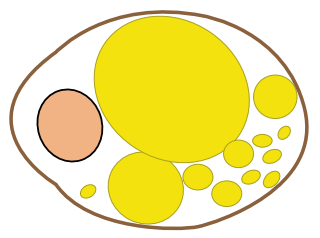

Gotas lipídicas
Condrocitos
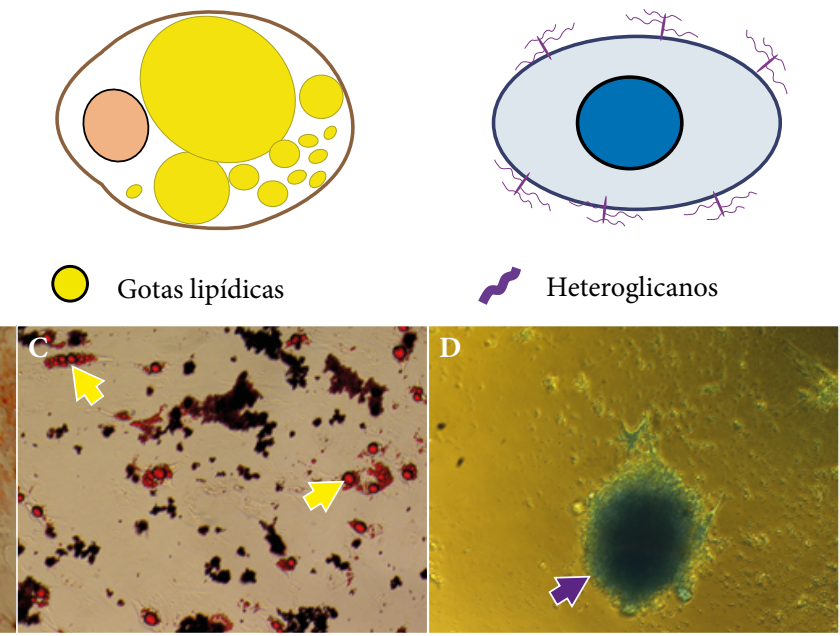

Figura 3. Esquema de diferenciación osteogénica, adipogénica y condrogénica a partir de: A. células madre/estromales derivadas de tejido adiposo (flecha blanca: colonia de células madre/estromales derivadas de tejido adiposo); B. caracterizados por presencia de depósitos de calcio (flecha negra); C. gotas lipídicas (flecha amarilla); y D. heteroglicanos (flecha morada), teñidos con los colorantes, Alzarin Red, Oil Red y Alcian Blue; respectivamente (A.T. $100 \mathrm{X}$ ).

OCT4, SOX2 y NANOG por medio de la presencia de bandas específicas.

\section{Control de calidad del cultivo}

Para monitorear la esterilidad del cultivo en el tiempo es importante verificar a diario que no haya contaminación por bacterias, hongos o levaduras las cuales pueden evidenciarse gracias a características macroscópicas como el cambio en el color del medio de cultivo, turbidez o incluso crecimiento de colonias y observarlas en un microscopio invertido. Sin embargo, hay microorganismos que no pueden ser visualizados en el microscopio, como es el caso de Mycoplasma sp., el cual es un contaminante frecuente en los cultivos celulares, para lo cual se debe realizar un ensayo de PCR con el fin de comprobar la esterilidad del medio de cultivo y ausencia de este microorganismo. En este trabajo, se usó el kit EZPCR Mycoplasma Test (Biological Industries) que contiene cebadores específicos para detectar una región del gen $16 \mathrm{~S}$ del ARN ribosómico del Mycoplasma sp. siguiendo las recomendaciones del fabricante. Luego, se realizó una corrida electroforética en un gel de agarosa al $2 \%$ que fue observada en el fotodocumentador.

En la Figura 4A se aprecia el gel de electroforesis de la muestra que contenía el medio de cultivo de las ASC; donde no se observó ninguna banda amplificada del gen $16 \mathrm{~S}$ de ARN ribosómico (ARNr) de Mycoplasma sp., lo que indica la ausencia de este microorganismo en el cultivo celular.

\section{Consideraciones éticas}

Este trabajo fue aprobado por el Comité Institucional de Ética de la Universidad Científica del Sur. Asimismo, se obtuvo el consentimiento informado de la paciente previo a la toma de muestra.

\section{IMPLICANCIAS Y LIMITACIONES DEL PROCEDIMIENTO}

El tejido adiposo es una fuente rica de células madre/estromales comparada con otros tejidos como médula ósea, pulpa dental, entre otros ${ }^{(16)}$; y el procedimiento descrito permite inicialmente aislarlas a partir de este tejido; sin embargo, esto no implica que se deban obviar los pasos posteriores del procedimiento, por el contrario, la correcta identificación y caracterización de sus propiedades biológicas son necesarias para asegurar que las células aisladas sean ASC y mantengan su potencialidad, la cual podría verse afectada por factores como: la epigenética ${ }^{(17)}$, edad del individuo ${ }^{(1)}$, toma de muestra ${ }^{(7)}$, entre otros.

Las limitaciones de este estudio están relacionadas con el costo de los insumos, uso de equipos especializados y el tiempo requerido; además de la pérdida de las características de stemness de las ASC en el cultivo a largo plazo. Por otro lado, el procedimiento detallado es susceptible a futuras mejoras en función a los nuevos estudios que identifiquen marcadores más específicos, así como tecnologías que aceleren este procedimiento. 


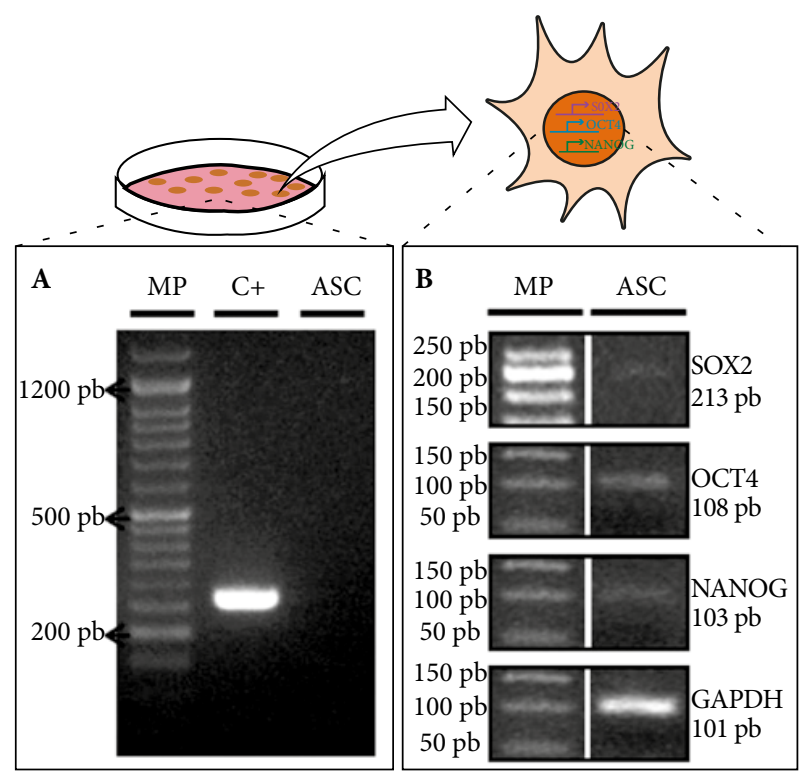

Figura 4. Prueba de presencia/ausencia de Mycoplasma sp. y análisis semicuantitavo por reacción en cadena de la polimerasa de transcripción inversa (RT-PCR). A. No se observa ninguna banda en el tercer carril del gel de electroforesis lo que indica la ausencia de Mycoplasma sp. en el medio de cultivo. B. En el segundo carril se observan bandas que indican la expresión de los genes SOX2, OCT4, NANOG y GAPDH con pesos moleculares de 213, 108, 103 y $101 \mathrm{pb}$; respectivamente. C+: control positivo de Mycoplasma sp., ASC: células madre/estromales derivadas de tejido adiposo, MP: marcador de peso molecular de 50 pares de bases, GAPDH: gliceraldehído 3 fosfato deshidrogenasa (gen de referencia)

\section{DISCUSIÓN}

Este trabajo detalló un procedimiento para el cultivo e identificación de ASC. La efectividad de este procedimiento se demostró mediante la identificación de las células aisladas, las cuales mostraron características propias de las MSC en función a su inmunofenotipo, capacidad de diferenciación y, adicionalmente, expresión de genes relacionados a la potencialidad. Asimismo, nuestros resultados coinciden con los obtenidos previamente en otros estudios ${ }^{(15,18)}$.

El porcentaje de células que expresaron los marcadores CD44, CD73 y CD90 es consistente con lo establecido por la ISCT ${ }^{(5)}$, a excepción de la expresión del marcador CD105, cuya expresión fue del 83,6\%. Este bajo nivel de expresión del marcador CD105 pudo haber sido causado por el uso de agentes enzimáticos disociadores como la tripsina ${ }^{(19)}$, el suero fetal bovino en el medio de cultivo ${ }^{(20)}$, entre otros factores, siendo este marcador el más susceptible a cambios en su expresión. Debido a la inestabilidad del marcador CD105, la ISCT propuso en 2013, la inclusión del marcador CD13 y/o el reemplazo del marcador $\mathrm{CD} 105$ por $\mathrm{CD} 13$ para la caracterización de ASC ya que, su expresión es más alta y estable ${ }^{(6)}$.
Las ASC identificadas en este trabajo se diferenciaron en osteocitos, adipocitos y condrocitos, pero cabe mencionar que existen estudios realizados donde demuestran que las ASC también pueden diferenciarse en hepatocitos ${ }^{(21)}$, células tipo pancreáticas ${ }^{(22)} \mathrm{y}$ células neuronales ${ }^{(15,23)}$.

La ISCT sugiere el uso de criterios adicionales para medir el potencial de diferenciación ${ }^{(6)}$, por tal motivo, se incluyó un paso adicional para evaluar la expresión génica de OCT4, SOX2 y NANOG. Los factores de transcripción OCT4, SOX2 y NANOG forman parte de una red reguladora transcripcional que juega un papel importante en el mantenimiento de la característica de stemness en las células madre. Nuestros resultados mostraron claramente la expresión de los genes OCT4 y NANOG y una menor expresión del gen SOX2 como se observa en la Figura 4B; a pesar de que, estos tres factores interactúan entre sí, se ha demostrado que NANOG y OCT4 tienen una función jerárquica en esta red que regula la pluripotencia, puesto que el silenciamiento de estos indujo la expresión de genes específicos de tejidos, por lo que son esenciales para mantener las propiedades de las MSC ${ }^{(7,8)}$. Estos estudios demuestran la importancia de evaluar la expresión de estos genes para determinar la potencialidad de las células madre/estromales aisladas de tejido adiposo.

En conclusión, en este trabajo experimental se detallan los procedimientos usados para aislar, identificar y caracterizar las células madre obtenidas a partir del lipoaspirado humano por el profesional que desee usar ASC en su trabajo de investigación. Asimismo, en este estudio se han evidenciado las propiedades biológicas fundamentales de estas células madre utilizando para el efecto técnicas de aislamiento que nos han permitido reconocerlas por citometría de flujo; se mostró el potencial de diferenciación en tres tipos celulares: osteocitos, adipocitos y condrocitos; se evidenció la expresión de los genes SOX2, OCT4 y NANOG por RT-PCR y se precisó la calidad de un cultivo libre de microorganismos contaminantes.

Contribuciones de autoría: STR, AMH y JAP concibieron y diseñaron el artículo, recolectaron información e hicieron la revisión crítica. PC y JEG aportaron el material de estudio. STR y AMH analizaron e interpretaron datos y elaboraron la discusión. Todos participaron en la redacción, aprobación de la versión final del artículo y asumen la responsabilidad de su contenido.

Financiamiento: Este trabajo fue financiado por la Universidad Científica del Sur y por el Consejo Nacional de Ciencia, Tecnología e Innovación Tecnológica (CONCYTEC), a través del proyecto «Evaluación del efecto de extractos y fracciones de tres plantas medicinales sobre células madre del cáncer gástrico», Contrato n. ${ }^{\circ}$ 134-2017-FONDECYT.

Agradecimientos: Al TM. José M. Guevara quien brindó el kit BD Bioscience para la caracterización de las ASC por citometría de flujo.

Conflictos de interés: Los autores declaran no tener ningún conflicto de interés.

Material suplementario: Disponible en la versión electrónica de la RPMESP. 


\section{REFERENCIAS BIBLIOGRÁFICAS}

1. Pittenger MF, Discher DE, Péault BM, Phinney DG, Hare JM, Caplan AI. Mesenchymal stem cell perspective: cell biology to clinical progress. NPJ Regen Med. 2019;4(1):1-15. doi: 10.1038/s41536-019-0083-6.

2. Pimentel-Parra GA, Murcia-Ordoñez B. Células madre, una nueva alternativa médica. Perinatol y Reprod Humana. 2017;31(1):28-33. doi: 10.1016/j.rprh.2017.10.013

3. Amiel-Pérez J, Casado F. Células madre: limitaciones y oportunidades en el Perú. Rev Peru Med Exp Salud Publica. 2015;32(4):777-86. doi: 10.17843/rpmesp.2015.324.1772.

4. Liu G, David BT, Trawczynski M, Fessler RG. Advances in pluripotent stem cells: history, mechanisms, technologies, and applications. Stem cell Rev reports. 2020;16(1):3-32. doi: 10.1007/s12015-019-09935-x.

5. Dominici M, Le Blanc K, Mueller I, Slaper-Cortenbach I, Marini FC, Krause DS, et al. Minimal criteria for defining multipotent mesenchymal stromal cells. The International Society for Cellular Therapy position statement. Cytotherapy. 2006;8(4):315-7. doi: 10.1080/14653240600855905.

6. Bourin P, Bunnell BA, Casteilla L, Dominici M, Katz AJ, March KL, et al. Stromal cells from the adipose tissue-derived stromal vascular fraction and culture expanded adipose tissue-derived stromal/stem cells: a joint statement of the International Federation for Adipose Therapeutics and Science (IFATS) and the International Society for Cellular Therapy. Cytotherapy. 2013;15(6):641-8. doi: 10.1016/j.jcyt.2013.02.006.

7. Pitrone M, Pizzolanti G, Tomasello L, Coppola A, Morini L, Pantuso $\mathrm{G}$, et al. NANOG plays a hierarchical role in the transcription network regulating the pluripotency and plasticity of adipose tissue-derived stem cells. Int J Mol Sci. 2017;18(6):1107. doi: 10.3390 / ijms18061107.

8. Tsai CC, Su PF, Huang YF, Yew TL, Hung SC. Oct4 and Nanog directly regulate Dnmtl to maintain self-renewal and undifferentiated state in mesenchymal stem cells. Mol Cell. 2012;47(2):169-82. doi: 10.1016/j. molcel.2012.06.020.

9. Millás-Mur J. Opinión de médicos peruanos sobre la aplicación actual de terapias con células madre. Acta Médica Peru. 2017;34(2):82-9. doi: 10.35663/amp.2017.342.314.

10. Pérez-Soto WA, Yance-Morales M, Pérez-Willis WA. Técnica de aislamiento de la fracción vascular estromal derivada del tejido adiposo: obtención de células madre adultas para diversas aplicaciones. Cirugía Plástica. 2020;29(2):202-9. doi: 10.35366/91712.

11. Tello-Vera S. Fibrosis pulmonar idiopática tratada con células madres mesenquimales alogénicas derivadas de tejido adiposo. Reporte de caso. Rev del Cuerpo Médico del HNAAA. 2018;11(4):250-2. doi: 10.35434/ rcmhnaaa.2018.114.468.
12. Vargas GZS, Chagua VMN, Álvarez CRP, Jáuregui AMM, Mendoza LÁA. Estudios en neurociencias: aportes para la investigación en cultivo de células madre mesenquimales. Persona. 2018;21(1):109-17. doi: 10.26439/ persona2018.n021.1993.

13. Tello-Vera S, Pairazamán-Sifuentes P, Fiestas-Fernández C, Marena-Hernández L. Insuficiencia renal tratada exitosamente con células madre. Rev del Cuerpo Médico del HNAAA. 2018;11(1):49-51. doi: 10.35434/ rcmhnaaa.2018.111.59.

14. Centurion P, Noriega A. Fat preserving by laser 1210-nm. J Cosmet Laser Ther. 2013;15(1):2-12. doi: 10.3109/14764172.2012.758376.

15. Zhu M, Heydarkhan-Hagvall S, Hedrick M, Benhaim P, Zuk P. Manual Isolation of Adipose-derived Stem Cells from Human Lipoaspirates. J Vis Exp. 2013;(79):e50585. doi: 10.3791/50585.

16. Kolaparthy LK, Sanivarapu S, Moogla S, Kutcham RS. Adipose tissue-adequate, accessible regenerative material. Int J stem cells. 2015;8(2):121. doi: 10.15283/ijsc.2015.8.2.121.

17. Tapia-Rojas S. La epigenética: alcances, aplicaciones y retos. Científica. 2017;14(2):41-4.

18. Tucker HA, Bunnell BA. Characterization of Human Adipose-Derived Stem Cells Using Flow Cytometry. En: Methods Mol Biol. 2011;702:12131. doi: 10.1007/978-1-61737-960-4_10.

19. Tsuji K, Ojima M, Otabe K, Horie M, Koga H, Sekiya I, et al. Effects of Different Cell-Detaching Methods on the Viability and Cell Surface Antigen Expression of Synovial Mesenchymal Stem Cells. Cell Transplant. 2017;26(6):1089-102. doi: 10.3727/096368917X694831.

20. Mark P, Kleinsorge M, Gaebel R, Lux CA, Toelk A, Pittermann E, et al. Human Mesenchymal Stem Cells Display Reduced Expression of CD105 after Culture in Serum-Free Medium. Stem Cells Int. 2013;2013:1-8. doi: $10.1155 / 2013 / 698076$

21. Xu D, Nishimura T, Zheng M, Wu M, Su H, Sato N, et al. Enabling Autologous Human Liver Regeneration with Differentiated Adipocyte Stem Cells. Cell Transplant. 2014;23(12):1573-84. doi: 10.3727/096368913X673432.

22. Lee J, Han DJ, Kim SC. In vitro differentiation of human adipose tissue-derived stem cells into cells with pancreatic phenotype by regenerating pancreas extract. Biochem Biophys Res Commun. 2008;375(4):547-51. doi: 10.1016/j.bbrc.2008.08.064.

23. Madhu V, Dighe AS, Cui Q, Deal DN. Dual Inhibition of Activin/Nodal/ TGF- $\beta$ and BMP Signaling Pathways by SB431542 and Dorsomorphin Induces Neuronal Differentiation of Human Adipose Derived Stem Cells. Stem Cells Int. 2016;2016:1035374. doi: 10.1155/2016/1035374. 